\title{
Anti-inflammatory effects of Lefty-1 in renal tubulointerstitial inflammation via regulation of the $\mathrm{NF}-\kappa \mathrm{B}$ pathway
}

\author{
LIJUN ZHANG ${ }^{1}, \mathrm{CHANGGENG} \mathrm{XU}^{2}$, WEI HU ${ }^{3}, \mathrm{PIN} \mathrm{WU}^{4}, \mathrm{CONG} \mathrm{QIN}^{4}$ and JIE ZHANG ${ }^{4}$ \\ ${ }^{1}$ Department of Urology, Minda Hospital Affiliated to Hubei Institute for Nationalities, Enshi, Hubei 445000; \\ ${ }^{2}$ Department of Urology, Wuhan Central Hospital, Wuhan, Hubei 430014; ${ }^{3}$ Department of Urology, \\ The First Affiliated Hospital of University of South of China, Hengyang, Hunan 421001; \\ ${ }^{4}$ Department of Urology, Renmin Hospital of Wuhan University, Wuhan, Hubei 430060, P.R. China
}

Received November 1, 2016; Accepted November 23, 2017

DOI: 10.3892/ijmm.2017.3327

\begin{abstract}
Renal tubulointerstitial inflammation has an important role in fibrosis, which is the main pathogenetic alteration associated with chronic kidney disease (CKD). The left-right determination factor 1 (Lefty-1) gene pleiotropically and biologically regulates transforming growth factor, mitogen-activated protein kinase and other signaling pathways, and is considered to have a potential anti-inflammatory function. However, its role in renal tubulointerstitial inflammation, which is often a long-term consequence of renal fibrosis, is currently unknown. In the present study, the effects of adenovirus-mediated overexpression of Lefty-1 (Ad-Lefty-1-flag) on renal tubulointerstitial inflammation were determined using a mouse model of unilateral ureteral obstruction (UUO) and a rat renal tubular duct epithelial cell line (NRK-52E), which was treated with lipopolysaccharide (LPS). In vivo results indicated that the inflammatory response was increased in UUO mice, as evidenced by the increase in inflammatory cytokines and chemokines. Conversely, Lefty-1 significantly reversed the effects of UUO. Furthermore, the results of the in vitro study demonstrated that Lefty-1 significantly inhibited LPS-induced inflammatory marker expression in cultured NRK-52E cells via the nuclear factor (NF)- $\mathrm{kB}$ signaling pathway. These results suggested that Lefty-1 may ameliorate renal tubulointerstitial inflammation by suppressing NF- $\mathrm{kB}$ signaling. In conclusion, the findings of the present study indicated that Lefty-1 may be considered a potential novel therapeutic agent for inhibiting renal tubulointerstitial inflammation or even reversing the CKD process.
\end{abstract}

Correspondence to: Dr Jie Zhang, Department of Urology, Renmin Hospital of Wuhan University, 9 Zhangzhidong Street, Wuhan, Hubei 430060, P.R. China

E-mail: zhangjie_doc@163.com

Abbreviations: CKD, chronic kidney disease; LPS, lipopolysaccharide; UUO, unilateral ureteral obstruction; DMEM, Dulbecco's modified Eagle's medium

Key words: left-right determination factor 1, lipopolysaccharide, renal inflammation, NRK-52E, unilateral ureteral obstruction

\section{Introduction}

Inflammation refers to the complex biological response of the body to various harmful stimuli, including pathogens, irritants, tissue necrosis, allergic reaction or cell damage. Inflammation is induced as a protective response to a wide range of injuries in an attempt to eliminate the cause of injury and promote repair. However, ongoing inflammation and chronic inflammatory processes may result in the pathogenesis of common inflammation-associated diseases, including chronic bronchitis, rheumatic heart disease, atherosclerosis and renal fibrosis $(1,2)$. Renal tubulointerstitial inflammation is an important characteristic of chronic kidney disease (CKD). Regardless of the initial cause, renal fibrosis is the common and final outcome of all progressive CKDs. Renal tubulointerstitial inflammation is generally considered an initial cause of renal fibrosis, and is associated with the infiltration of inflammatory cells into glomeruli and peritubular capillaries, particularly macrophages and neutrophils, during the early events of fibrogenesis (3). In renal tubulointerstitial inflammation and fibrosis, the nuclear factor (NF)- $\mathrm{\kappa B}$ signaling pathways serve a critical role in CKD development and progression. Numerous studies have indicated that inflammation and fibrosis are closely related; therefore, a lack of inflammation is associated with a lack of fibrosis (4-6). Early intervention and inflammatory control in fibrosis and CKD treatment are critical.

In renal tubulointerstitial inflammation, the renal tubular epithelial cells are not only damaged but are also induced to secrete numerous extracellular matrix factors and inflammatory chemokines, which actively participate in renal interstitial fibrosis. Proinflammatory cytokines and profibrotic factors are secreted by renal tubular epithelial cells following injury, thereby causing renal tubulointerstitial inflammation. In the present study, the NRK-52E cell line was selected due to the important role of renal tubular epithelial cells in renal inflammation. In addition, lipopolysaccharide (LPS), which is a product of Gram-negative bacteria, is an important inflammatory factor that exerts host toxicity. LPS, or endotoxin, is released in response to Gram-negative bacterial death and dissolution. Previous studies have reported that LPS induces fever and leukocyte reaction in renal inflammatory models when studying inflammatory renal disease $(7,8)$. In mouse and other animal models, LPS-induced renal tubulointerstitial inflammation is 
accompanied with a marked inflammatory response, including glomerular and peritubular leukocyte infiltration $(9,10)$.

In vivo mature renal inflammatory models have been created using unilateral ureteral obstruction (UUO), which is a classical model for the study of renal interstitial fibrosis and inflammation. Renal obstruction caused by UUO leads to increased urinary pressure, decreased renal blood flow, venous drainage obstruction, infiltration of inflammatory cells and proliferation of fibroblasts, thus leading to renal failure. This model has been used in numerous studies regarding renal inflammation $(11,12)$. In addition, LPS may induce a multisystemic inflammatory response; however, the specific renal inflammatory response was reduced in vivo LPS treatment. These models were used in the present study to determine the effects of left-right determination factor 1 (Lefty-1) on renal tubulointerstitial inflammation.

Lefty is a novel member of the transforming growth factor (TGF)- $\beta$ superfamily. Lefty possesses two variants in mice: Lefty- 1 and Lefty-2, whereas Lefty-A and Lefty-B have been detected in humans. These proteins control embryonic development, and regulate stem cell differentiation and other functions (13). A previous study demonstrated that Lefty may inhibit TGF- $\beta 1$ signaling by reducing Smad2/3 phosphorylation, and further suppressing nuclear translocation of the R-Smad (Smad2/3)/Smad4 complex (14). Furthermore, the Lefty protein can regulate the cell cycle, and inhibit decidualization of the endometrium and tumor activity (15-17). Based on these data, various biological functions of Lefty have been revealed, and it has received widespread attention regarding its biological regulatory potential. However, despite the availability of information regarding the beneficial properties of Lefty, it is currently unknown as to whether this protein can regulate $\mathrm{NF}-\kappa \mathrm{B}$ signaling, and its effects on renal tubulointerstitial inflammation and renal fibrosis require elucidation. Therefore, the present study investigated whether Lefty-1 serves a regulatory role in renal tubulointerstitial inflammation and explored the possible mechanisms involved in its action.

It has previously been reported that Lefty attenuates renal tubulointerstitial injury in mice with UUO (18). In the present study, the protective effects of Lefty-1 on renal tubulointerstitial inflammation were further assessed. The present study initially investigated the effects of Lefty-1 on the expression and secretion of LPS-induced inflammatory markers in cultured NRK-52E cells in vitro and in a UUO model in vivo. Furthermore, the regulatory role of the NF- $\kappa \mathrm{B}$ signaling pathway in the potential protective effects of Lefty- 1 on renal interstitial inflammation was analyzed. Through in vitro and in vivo models, the present study aimed to evaluate the effects of Lefty-1 on renal tubulointerstitial inflammation and to gain a preliminary understanding of its underlying mechanism.

\section{Materials and methods}

Reagents and recombinant adenovirus. Interleukin (IL)-1 $\beta$ (cat. no. sc-7884; 1:100), IL-6 (cat. no. sc-7920; 1:200), tumor necrosis factor (TNF)- $\alpha$ (cat. no. sc-8301; 1:100), monocyte chemotactic protein(MCP)-1 (cat.no.sc-28879; 1:200),Smad7 (cat.no.sc-11392; 1:200), fibronectin (cat. no. sc-9068; 1:200), collagen I (A1) (cat. no. sc-28657; 1:200), cluster of differentiation (CD)68 (cat. no. sc-9139; 1:100), F4/80 (cat. no. sc-25830; 1:200) and $\alpha$-smooth muscle actin ( $\alpha$-SMA; cat. no. sc-53015; 1:300) antibodies were purchased from Santa Cruz Biotechnology, Inc. (Dallas, TX, USA). NF-кB-p65 (cat. no. 8242; 1:200), NF-кB-phosphorylated

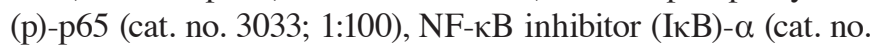
4812; 1:100) and p-IкB- $\alpha$ (cat. no. 2859; 1:200) antibodies were purchased from Cell Signaling Technology, Inc. (Danvers, MA, USA). Flag (cat. no. PAB25505; 1:200) antibodies were purchased from Abnova (Taipei, Taiwan). Lefty-1 (cat. no. H00010637-D01P; 1:200) antibodies were purchased from the Novus Biologicals LLC (Littleton, CO, USA). With the exception of anti- $\alpha$-SMA, which was derived from mouse, all antibodies were monoclonal and derived from rabbit. Dulbecco's modified Eagle's medium (DMEM)/high glucose medium and bovine serum albumin (BSA) were purchased from Gibco (Thermo Fisher Scientific, Inc., Waltham, MA, USA). LPS was obtained from Sigma-Aldrich (Merck KGaA, Darmstadt, Germany). The EZ-Cytox cell viability assay kit (MTT) was acquired from MultiSciences Biotech Co., Ltd. (Hangzhou, China). ELISA kits (cat. nos. EK0390,EK0412, EK0902 and EK0526) were obtained from Wuhan Boster Biological Technology Ltd. (Wuhan, China). The RevertAid First Strand cDNA Synthesis and quantitative polymerase chain reaction (PCR) kits were obtained from Takara Bio, Inc. (Otsu, Japan). Recombinant mice Lefty-1 adenovirus (Ad-Lefty-1) was packaged and identified by Vigene Biosciences, Inc. (Rockville, MD, USA).

Adenovirus construction. First-generation adenovirus was regulated by the cytomegalovirus promoter using an open reading frame (ORF) Shuttling system (Vigene Biosciences, Inc.). Briefly, mouse Lefty-1 cDNA (Vigene Biosciences, Inc.) was excised from the pENTR vector and inserted into a pAD-ORF transfer vector. The resulting plasmids were cotransformed into bacteria (E. coli) alongside human adenovirus type 5 (E1 and $\mathrm{E} 3$ deleted). The recombinant adenoviral constructs were transfected into 293 cells, in order to generate a recombinant adenovirus with a high Ad-Lefty- 1 titer $\left[1 \times 10^{10}\right.$ plaque-forming unit $(\mathrm{pfu}) / \mathrm{ml}]$. The doses used were selected based on a previous report (19). Recombinant adenoviruses can express exogenous gene fragments, and can infect dividing and non-dividing cells in a wide range of hosts. The present study obtained Ad-Lefty-1 through a customized adenovirus service (by Vigene Biosciences, Inc.). In the present study, Ad-control refers to an empty adenovirus that was used as a control in vivo and in vitro. To detect infection efficiency, all adenovirus vectors were labeled with flag. In addition, the effects of adenovirus infection were verified using western blot analysis, in order to confirm that Lefty-1 was highly expressed.

Cell culture and adenovirus infection. NRK-52E cells were purchased from the American TypeCulture Collection(Manassas, VA, USA). The cells were cultured in DMEM/high glucose medium supplemented with $10 \%$ fetal bovine serum (FBS; Gibco; Thermo Fisher Scientific, Inc.), $1 \%$ streptomycin and penicillin in humidified incubator containing $95 \%$ air and $5 \% \mathrm{CO}_{2}$ at $37^{\circ} \mathrm{C}$. The NRK-52E cells (70-80\% confluence) were seeded in 6-well plates, in order to determine the function of Lefty-1 on LPS-induced inflammation. The cells were divided into the following four groups: Control group, LPS $(5 \mu \mathrm{g} / \mathrm{ml})$ treatment group, LPS + Ad-control group, and LPS + Ad-Lefty-1 group. Firstly, the cells were transfected with adenovirus at $10 \mathrm{pfu} / \mathrm{cell}$ in $1.5 \%$ serum DMEM/high glucose medium (antibiotics-free) 
for $6 \mathrm{~h}$, and then LPS + Ad-control and LPS + Ad-Lefty-1 groups were washed with PBS and substitution of fresh media containing LPS was made for $24 \mathrm{~h}$. The fresh media were replaced with DMEM/high glucose medium containing 1.5\% FBS without antibiotics. The control group received no treatment, expressions of related proteins and genes were determined.

Animals and treatments. All animal studies were performed in accordance with the Chinese Council on Animal Care Guidelines. The present study was approved by the Animal Research Ethics Board of Wuhan University (Wuhan, China). Male C57BL/6 mice (age, 6-7 weeks; weight, 20-25 g) were obtained from the Wuhan University of Laboratory Animal Research (Wuhan, China) and were divided into the following experimental groups ( $n=7 /$ group): i) Sham, in which mice underwent a sham operation; ii) UUO (7 days); iii) UUO (7 days) + Ad-control; and iv) UUO (7 days) + Ad-Lefty-1. Anesthesia was induced and maintained by intraperitoneal injection of pentobarbital sodium $(50 \mathrm{mg} /$ $\mathrm{kg}$ body weight) (20). After general anesthesia, with the exception of the sham group, mice in the other experimental groups were subjected to UUO. Briefly, a midline abdominal incision was made, followed by double ligation of the upper left ureter using 4-0 silk sutures. The sham-operated mice had their ureters exposed but not ligated. The left kidneys were then wrapped with ice-cold saline-soaked gauze for $5 \mathrm{~min}$ post-injection, and $0.1 \mathrm{ml}$ cold saline containing $5.0 \times 10^{8}$ pfu Ad-control or Ad-Lefty-1 was injected into the left renal artery. The adenovirus solution, alongside 3 units heparin, was injected using a Hamilton 800 microsyringe (Hamilton, Reno, NV, USA). The mice were maintained under sterile conditions and were euthanized by cervical dislocation on postoperative day 7 . The left and right kidneys were separately obtained for RNA and histological analyses.

Cytotoxicity assay. The MTT assay was performed to detect the survival of NRK-52E cells. In the presence of an electronic-coupling reagent, mitochondrial dehydrogenase may be reduced to form orange formazan. Following treatment, the experimental cells were seeded into 96-well plates at a density of $6.0 \times 10^{3}$ cells/well. Subsequently, $10 \mu \mathrm{l}$ MTT reagent was added to the plates for $45 \mathrm{~min}$ at $37^{\circ} \mathrm{C}$, according to the manufacturer's protocol. Cytotoxicity was measured at 2, 4 and 6 h. Optical density (OD) in each well was determined at $460 \mathrm{~nm}$ using a PerkinElmer VICTOR3 1420 Multilabel Counter (PerkinElmer, Inc., Waltham, MA, USA). The MTT assay was repeated three times.

Detection of cytokine levels in cultured supernatants. Treated cells were seeded into 6-well plates at a density of $1.0 \times 10^{6}$ cells/well. The expression levels of inflammatory cytokines, IL-1, IL-6, MCP-1 and TNF- $\alpha$, were measured in the supernatant using ELISA kits according to the manufacturer's protocol. The standards and samples were added to the wells and were incubated at $37^{\circ} \mathrm{C}$ for $90 \mathrm{~min}$, after which biotin-labeled antibody was added for $60 \mathrm{~min}$ at $37^{\circ} \mathrm{C}$. After washing with PBS three times, avidin-peroxidase complex was added to the wells at $37^{\circ} \mathrm{C}$ for $30 \mathrm{~min}$ and the samples were then washed with PBS a further three times. Subsequently, the chromogenic substrate TMB was added to each well at $37^{\circ} \mathrm{C}$ for $25 \mathrm{~min}$. Finally, wells were treated with TMB stop solution, after which $\mathrm{OD}$ values were determined.
Reverse transcription-quantitative polymerase chain reaction $(R T-q P C R)$. Total RNA was extracted from cultured NRK-52E cells and tissues using TRIzol ${ }^{\circledR}$ reagent (Invitrogen; Thermo Fisher Scientific, Inc.). RNA was then reverse transcribed into cDNA, which was amplified by qPCR PrimeScript One-Step RT-PCR kit (Takara Bio, Inc.). The primer sequences are presented in Tables I and II. The reaction conditions were as follows: Predenaturation at $95^{\circ} \mathrm{C}$ for $30 \mathrm{sec}$, followed by 40 cycles at $95^{\circ} \mathrm{C}$ for $5 \mathrm{sec}$ and $60^{\circ} \mathrm{C}$ for $40 \mathrm{sec}$; extension at $95^{\circ} \mathrm{C}$ for $5 \mathrm{sec}$ followed by 40 cycles at $60^{\circ} \mathrm{C}$ for $30 \mathrm{sec}$. GAPDH was used as the reference gene. Relative quantification of gene expression was performed using the $2^{-\Delta \Delta \mathrm{Cq}}$ method (21). The results of qPCR are presented as the means \pm standard deviation of fold-change of expression.

Immunofluorescence staining. NRK-52E cells were fixed on coverslips with $4 \%$ paraformaldehyde for $20 \mathrm{~min}$ at room temperature, washed three times with PBS and permeabilized with $0.5 \%$ Triton X-100 buffer for 5 min. Subsequently, the cells were blocked with $1 \% \mathrm{BSA}$ in PBS for $20 \mathrm{~min}$ at $4^{\circ} \mathrm{C}$. The slides were then incubated overnight at $4^{\circ} \mathrm{C}$ with the following primary monoclonal antibodies: Anti-NF-кB-p65 (1:100), anti-fibronectin (1:200), anti-collagen I (1:200), anti-CD68 (1:100), anti-F4/80 (1:200) and anti- $\alpha$-SMA (1:300). The cells were then incubated with cyanine dye $(\mathrm{Cy} 3)$ - or fluorescein isothiocyanate (FITC)-conjugated secondary antibodies $(1: 100)$ to visualize the primary antibodies. Finally, the nuclei were counterstained with 4,6-diamidino-2-phenylindole. The slides were visualized under an Olympus BX51 fluorescence upright microscope (Olympus Corporation, Tokyo, Japan). Each experiment was repeated three times.

Histological examination. All renal tissue specimens were examined for morphological alterations. One half of each of the kidneys was fixed in $4 \%$ buffered paraformaldehyde for $24 \mathrm{~h}$ at room temperature for histological studies; the other half was snap-frozen in liquid nitrogen, and stored at $-80^{\circ} \mathrm{C}$ prior to protein or mRNA extraction. Briefly, tissues were embedded in paraffin and serial sections were made $(4 \mu \mathrm{m})$. The first study were used for morphological studies such as hematoxylin and eosin (H\&E) staining, and further analyses included immunohistochemistry, immunofluorescence, real-time polymerase chain reaction (RT-PCR). Immunostaining was analyzed in a blinded fashion. The antibodies used were as follows: IL-1 (1:100), IL-6 (1:200), MCP-1 (1:200), TNF- $\alpha$ (1:100), NF-кB-p-p65 (1:100), Smad7 (1:200), fibronectin $(1: 200)$, collagen I (1:200) and $\alpha$-SMA (1:300). After immunostaining with primary antibodies (which were incubated at $4^{\circ} \mathrm{C}$ overnight), the sections were developed using 3,3'-diaminobenzidine for immunohistochemical examination. Subsequently, sections were incubated with Cy3-conjugated goat anti-mouse (cat. no. 115-005-003; 1:200) and FITC-conjugated goat anti-rabbit secondary antibodies (cat. no. 111-005-003; 1:200) (both from Jackson ImmunoResearch Laboratories, Inc., West Grove, PA, USA) for immunohisto-fluorescence (avoid light incubating for $1 \mathrm{~h}$ at $37^{\circ} \mathrm{C}$ ). The histological images were viewed under an Olympus BX51 upright microscope (Olympus Corporation). Image-Pro Plus 7.0 (Media Cybernetics, Inc., Rockville, MD, USA) was used to semi-quantitatively analyze the positive signals. 
Table I. Mouse primers for quantitative polymerase chain reaction.

\begin{tabular}{|c|c|c|c|}
\hline Gene name & Gene ID & Primer sequences & Amplicon size (bp) \\
\hline$\alpha-\mathrm{SMA}$ & NM_007392.3 & $\begin{array}{l}\text { F: 5'-CTGGCATCGTGCTGGACTC-3' } \\
\text { R: 5'-GCCCATCAGGCAACTCGTA-3' }\end{array}$ & 291 \\
\hline Collagen I (A1) & NM_007743.3 & $\begin{array}{l}\text { F: 5'-TCCAAAGGAGAGAGCGGTAA-3' } \\
\text { R: 5'-GACCAGGGAGACCAAACTCA-3' }\end{array}$ & 310 \\
\hline Fibronectin & NM_173182.2 & $\begin{array}{l}\text { F: 5'-GATGATGACCGACCAGATCCC-3' } \\
\text { R: 5'-TGCTTCTCCGTTCACCAAGTG-3' }\end{array}$ & 88 \\
\hline TNF- $\alpha$ & NM_013693.3 & $\begin{array}{l}\text { F: 5'-CCCTCACACTCAGATCATCTTCT-3' } \\
\text { R: 5'-GCTACGACGTGGGCTACAG-3' }\end{array}$ & 61 \\
\hline IL-6 & NM_031168.2 & $\begin{array}{l}\text { F: 5'-TAGTCCTTCCTACCCCAATTTCC-3' } \\
\text { R: 5'-TTGGTCCTTAGCCACTCCTTC-3' }\end{array}$ & 76 \\
\hline IL-1 $\beta$ & NM_008361.4 & $\begin{array}{l}\text { F: 5'-CTGTGACTCATGGGATGATGATG-3' } \\
\text { R: 5'-CGGAGCCTGTAGTGCAGTTG-3' }\end{array}$ & 75 \\
\hline MCP-1 & NM_011333.3 & $\begin{array}{l}\text { F: 5'-TAAAAACCTGGATCGGAACCAAA-3' } \\
\text { R: 5'-GCATTAGCTTCAGATTTACGGGT-3' }\end{array}$ & 120 \\
\hline Smad7 & NM_001042660.1 & $\begin{array}{l}\text { F: 5'-GTGTTGCTGTGAATCTTACG-3' } \\
\text { R: 5'-AGAAGAAGTTGGGAATCTGA-3' }\end{array}$ & 228 \\
\hline $\mathrm{NF}-\kappa \mathrm{B}-\mathrm{p} 65$ & NM_001357627.1 & $\begin{array}{l}\text { F: 5-CCCTCGAGATGGACGATCTGTTTCCCCT-3' } \\
\text { R: 5-CCCAAGCTTTTAGGAGCTGATCTGACTC-3' }\end{array}$ & 211 \\
\hline GAPDH & NM_008084.3 & $\begin{array}{l}\text { F: 5'-TGACCTCAACTACATGGTCTACA-3' } \\
\text { R: 5'-CTTCCCATTCTCGGCCTTG-3' }\end{array}$ & 85 \\
\hline
\end{tabular}

$\alpha$-SMA, $\alpha$-smooth muscle actin; F, forward; IL, interleukin; MCP-1, monocyte chemotactic protein-1; NF- $\kappa \mathrm{B}$, nuclear factor- $\kappa \mathrm{B}$; R, reverse; TNF- $\alpha$, tumor necrosis factor- $\alpha$.

Table II. Rat primers for quantitative polymerase chain reaction.

\begin{tabular}{|c|c|c|c|}
\hline Gene name & Gene ID & Primer sequences & Amplicon size (bp) \\
\hline TNF- $\alpha$ & NM_012675.3 & $\begin{array}{l}\text { F: 5'-TGCCTCAGCCTCTTCTCATT-3' } \\
\text { R: 5'-GGGCTTGTCACTCGAGTTTT-3' }\end{array}$ & 180 \\
\hline IL-6 & NM_012589.2 & $\begin{array}{l}\text { F: 5'-AGTTGCCTTCTTGGGACTGA-3' } \\
\text { R: 5'-ACAGTGCATCATCGCTGTTC-3' }\end{array}$ & 218 \\
\hline IL-1 $\beta$ & NM_031512.2 & $\begin{array}{l}\text { F: 5'-CTGTGACTCGTGGGATGATG-3' } \\
\text { R: 5'-AGGGATTTTGTCGTTGCTTG-3' }\end{array}$ & 211 \\
\hline MCP-1 & NM_031530.1 & $\begin{array}{l}\text { F: 5'-GATGCAGTTAATGCCCCACT-3' } \\
\text { R: 5'-TTCCTTATTGGGGTCAGCAC-3' }\end{array}$ & 168 \\
\hline$\alpha$-SMA & NM_031004.2 & $\begin{array}{l}\text { F: 5'-AACTGGTATTGTGCTGGACTCTG-3' } \\
\text { R: 5'-CTCAGCAGTAGTCACGAAGGAATA-3' }\end{array}$ & 172 \\
\hline Collagen I (A1) & NM_053304.1 & $\begin{array}{l}\text { F: 5'-CAGATTGAGAACATCCGCAGC-3' } \\
\text { R: 5'-CGGAACCTTCGCTTCCATACTC-3' }\end{array}$ & 310 \\
\hline Fibronectin & NM_019143.2 & $\begin{array}{l}\text { F: 5'-GTGATCTACGAGGGACAGC-3' } \\
\text { R: 5'-GCTGGTGGTGAAGTCAAAG-3' }\end{array}$ & 78 \\
\hline GAPDH & NM_017008.4 & $\begin{array}{l}\text { F: 5'-GGGTGTGAACCACGAGAAAT-3' } \\
\text { R: 5'-ACTGTGGTCATGAGCCCTTC-3' }\end{array}$ & 135 \\
\hline
\end{tabular}

$\alpha$-SMA, $\alpha$-smooth muscle actin; F, forward; IL, interleukin; MCP-1, monocyte chemotactic protein-1; R, reverse; TNF- $\alpha$, tumor necrosis factor- $\alpha$. 
A

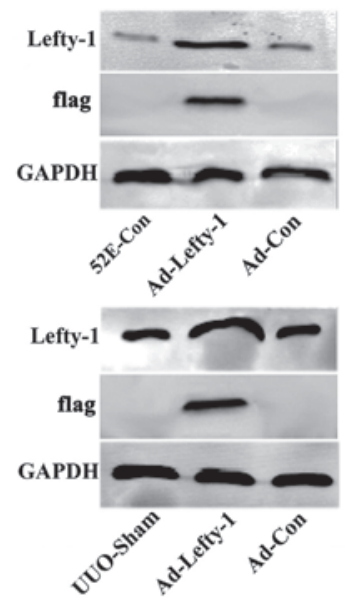

C

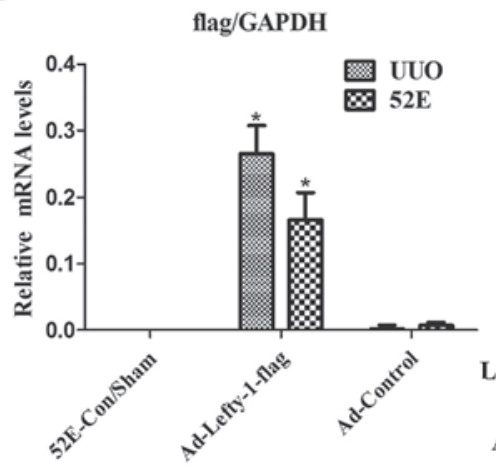

B

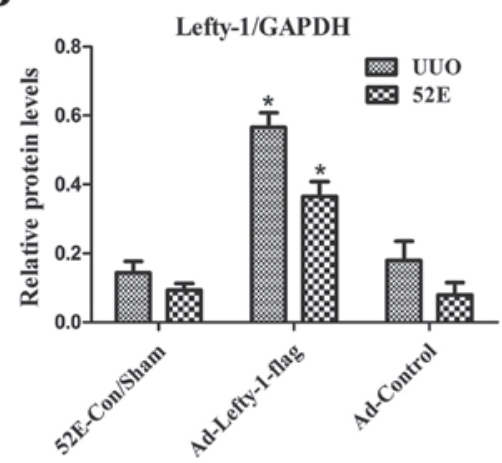

D

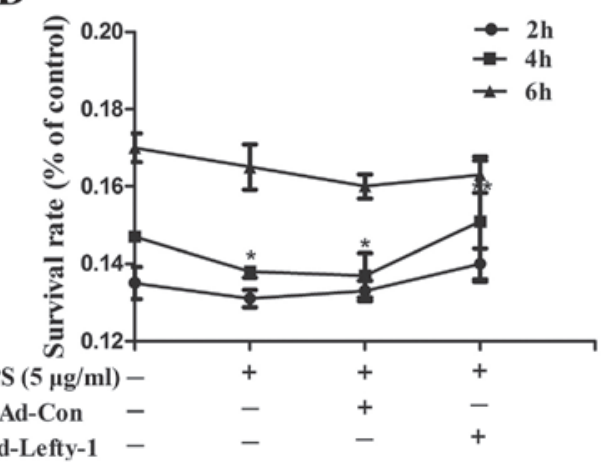

Figure 1. (A and B) Protein and (C) mRNA expression levels of Lefty-1 and flag in response to Ad-Lefty-1 infection were determined by western blot analysis and reverse transcription-quantitative polymerase chain reaction analysis, respectively. (D) Effects of Ad-Lefty-1 on cytotoxicity in LPS-induced NRK-52E cells were determined by MTT assay. Experiments were performed at least three times with similar results. $\mathrm{n}=5$. $^{*} \mathrm{P}<0.001 \mathrm{vs}$. the control group; ${ }^{* *} \mathrm{P}<0.05 \mathrm{vs}$. the LPS $(5 \mu \mathrm{g} / \mathrm{ml})$ or LPS + Ad-control-treated groups. Ad, adenovirus; Lefty-1, left-right determination factor 1; LPS, lipopolysaccharide; UUO, unilateral ureteral obstruction.

Western blot analysis. Total proteins were extracted using radioimmunoprecipitation assay lysis buffer containing protease inhibitor cocktail (Wuhan Goodbio Technology Co., Ltd., Wuhan, China) and protein concentrations were measured using the bicinchoninic acid assay kit (Wuhan Boster Biological Technology Ltd.). Equal amounts of total protein $(30 \mu \mathrm{g})$ were loaded into each lane, separated by $10 \%$ SDS-PAGE and transferred onto activated polyvinylidene fluoride membranes. After blocking with 5\% BSA in Tris-buffered saline at room temperature for $1 \mathrm{~h}$, the membranes were incubated overnight at $4^{\circ} \mathrm{C}$ with the appropriate primary antibodies. Subsequently, the membranes were incubated with fluorescence-labeled secondary antibodies [IRDye700 and IRDye800, goat anti-mouse (cat. no. 925-32210; 1:1,000)/rabbit (cat. no. 925-32211; 1:1,000); both from LI-COR Biosciences, Lincoln, NE, USA] for $1 \mathrm{~h}$ at $37^{\circ} \mathrm{C}$, and immune complexes were detected using an Odyssey infrared imaging system (https://www.licor.com/bio/products/imaging_systems/ odyssey/; LI-COR Biosciences).

Statistical analysis. All statistical analyses were performed using SPSS 19.0 (IBM Corp., Armonk, NY, USA). Data are expressed as the means \pm standard deviation. One-way analysis of variance, followed by the Student-Newman-Keuls test, was used for the quantitative data, whereas the Kruskal-Wallis test was used for non-normally distributed data. $\mathrm{P}<0.05$ was considered to indicate a statistically significant difference.

\section{Results}

Adenovirus-mediated Lefty-1 overexpression inhibits LPS-induced NRK-52E cytotoxicity. Western blot analysis and RT-qPCR were used to examine Lefty-1 overexpression, and validate Ad-Lefty-1 infection efficiency in NRK-52E cells and in UUO mice. The results indicated that the expression levels of Lefty-1 were significantly higher in NRK-52E cells and UUO mice stably infected with Ad-Lefty-1 compared with in the uninfected NRK-52E cells and the sham group mice (Fig. 1A-C). NRK-52E cytotoxicity was evaluated using the MTT assay. Cytotoxicity was not detected in the control groups. Conversely, LPS markedly enhanced NRK-52E cytotoxicity, particularly $4 \mathrm{~h}$ after treatment, whereas Ad-Lefty-1 infection significantly suppressed LPS-induced cytotoxicity (Fig. 1D).

Lefty-1 overexpression suppresses the release of inflammatory mediators and macrophage infiltration. The present study aimed to determine the protective function of Lefty-1 on the suppression of proinflammatory mediators and macrophage infiltration in vivo via histological examination and RT-qPCR. As shown in Fig. 2, mice exhibited progressive tubulointerstitial damage, which was characterized by tubular dilation with flattened epithelium, and tubular and glomerular atrophy, on day 7 following UUO. In addition, expansion of the renal interstitial space, and inflammatory cytokine (IL-1 $\beta$, IL- 6 and TNF- $\alpha$ ) and chemokine (MCP-1) expression were increased alongside 

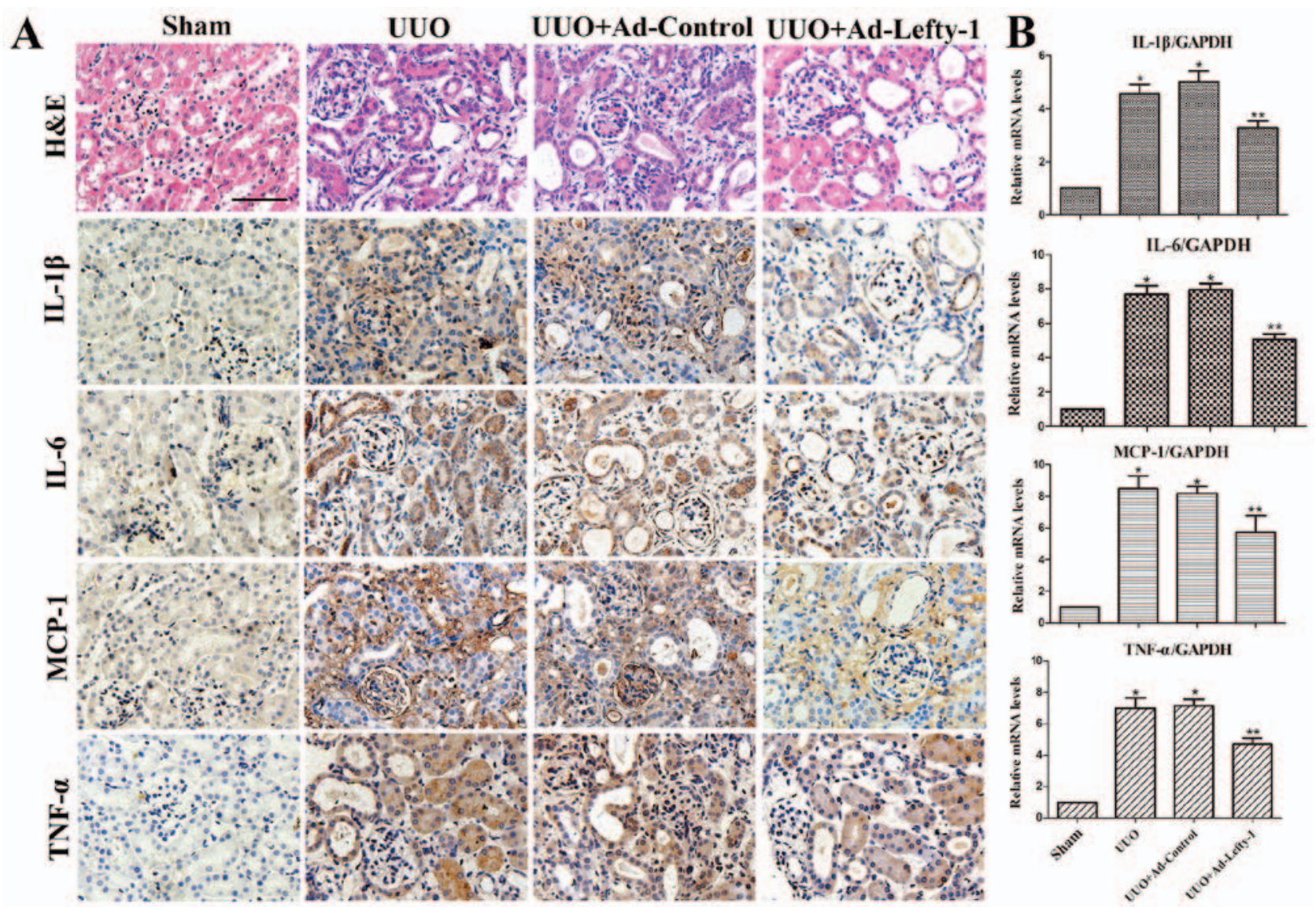

Figure 2. Effects of Lefty-1 on UUO-induced renal tubulointerstitial inflammation. (A) Overexpression of Lefty-1 suppressed inflammatory cytokine (IL-1 $\beta$, IL-6 and TNF- $\alpha$ ) and chemokine (MCP-1) expression 7 days after UUO, as determined by immunohistochemistry. Magnification, x200; scale bar, $20 \mu \mathrm{m}$ (B) Reverse transcription-quantitative polymerase chain reaction. Data are expressed as the means \pm standard deviation of at least three independent experiments. $\mathrm{n}=6$. ${ }^{*} \mathrm{P}<0.001$ vs. the sham control group; ${ }^{* *} \mathrm{P}<0.05$ vs. the UUO or UUO + Ad-control-treated groups. Ad, adenovirus; H\&E, hematoxylin and eosin; IL, interleukin; Lefty-1, left-right determination factor 1; MCP-1, monocyte chemotactic protein-1; TNF- $\alpha$, tumor necrosis factor- $\alpha$; UUO, unilateral ureteral obstruction.

progressive inflammation. Furthermore, immunofluorescence staining indicated that CD68 and F4/80 expression, and positive macrophage infiltration, were increased in UUO mice compared with in sham-operated mice (Fig. 3). These increases were not significantly inhibited by Ad-control. Conversely, Ad-Lefty-1 infection suppressed macrophage infiltration, and inflammatory cytokine and chemokine expression. These findings suggested that Ad-Lefty-1-induced improvement of histological damage was associated with a reduction in inflammation.

Lefty-1 overexpression suppresses LPS-induced NF- $\kappa B-p-p 65$ nuclear translocation in vitro. The present study performed immunofluorescence staining to examine the distribution of NF- $\mathrm{NB}-\mathrm{p}-\mathrm{p} 65$ and to confirm that Lefty-1 inhibited LPS-induced nuclear translocation of NF- $\mathrm{B}-\mathrm{p}-\mathrm{p} 65$ in NRK-52E cells. The results indicated that NF- $\kappa B-p-p 65$ protein was predominately detected in the cytoplasm of normal cells (Fig. 4). Following LPS stimulation for $1 \mathrm{~h}$, increased NF- $\kappa \mathrm{B}-\mathrm{p}-\mathrm{p} 65$ staining was observed in the nucleus. Conversely, Ad-Lefty-1 could decrease NF- $\mathrm{B}-\mathrm{p}-\mathrm{p} 65$ nuclear staining, thus suggesting that Lefty-1 inhibited NF- $\mathrm{B}-\mathrm{p}-\mathrm{p} 65$ nuclear translocation. However, Ad-control infection had no affect on NF- $\mathrm{B}-\mathrm{p}-\mathrm{p} 65$ nuclear staining.
Lefty-1 overexpression attenuates LPS-induced inflammatory responses in NRK-52E cells. The present study also aimed to determine whether Lefty- 1 affects the synthesis of proinflammatory cytokines (IL-1 $\beta$, IL-6 and TNF- $\alpha$ ) and chemokines (MCP-1) in LPS-treated cells. Based on the results of ELISA analyses (Fig. 5), the expression levels of these inflammatory proteins were significantly increased in LPS-challenged NRK-52E cells. However, infection with Ad-Lefty-1 significantly decreased cytokine and chemokine expression. These in vitro results were similar to those observed in the in vivo analyses. These findings indicated that Lefty-1 may mediate the inhibition of proinflammatory cytokines and chemokines.

Lefty-1 overexpression inhibits renal fibrosis in vivo and in vitro. Inflammation is a protective response in numerous types of kidney injury; however, unresolved inflammation promotes progressive renal fibrosis (4). Therefore, the present study assessed the expression of fibrotic proteins, in order to verify the association between fibrosis and inflammation.

The effects of Lefty-1 were determined on fibrosis in vivo and in vitro (Fig. 6). Immunofluorescence staining and RT-qPCR analysis indicated that the expression levels of fibronectin, collagen I and $\alpha$-SMA were increased in kidneys from UUO mice compared with in the sham-operated kidneys (Fig. 6A and C). This increase was significantly 

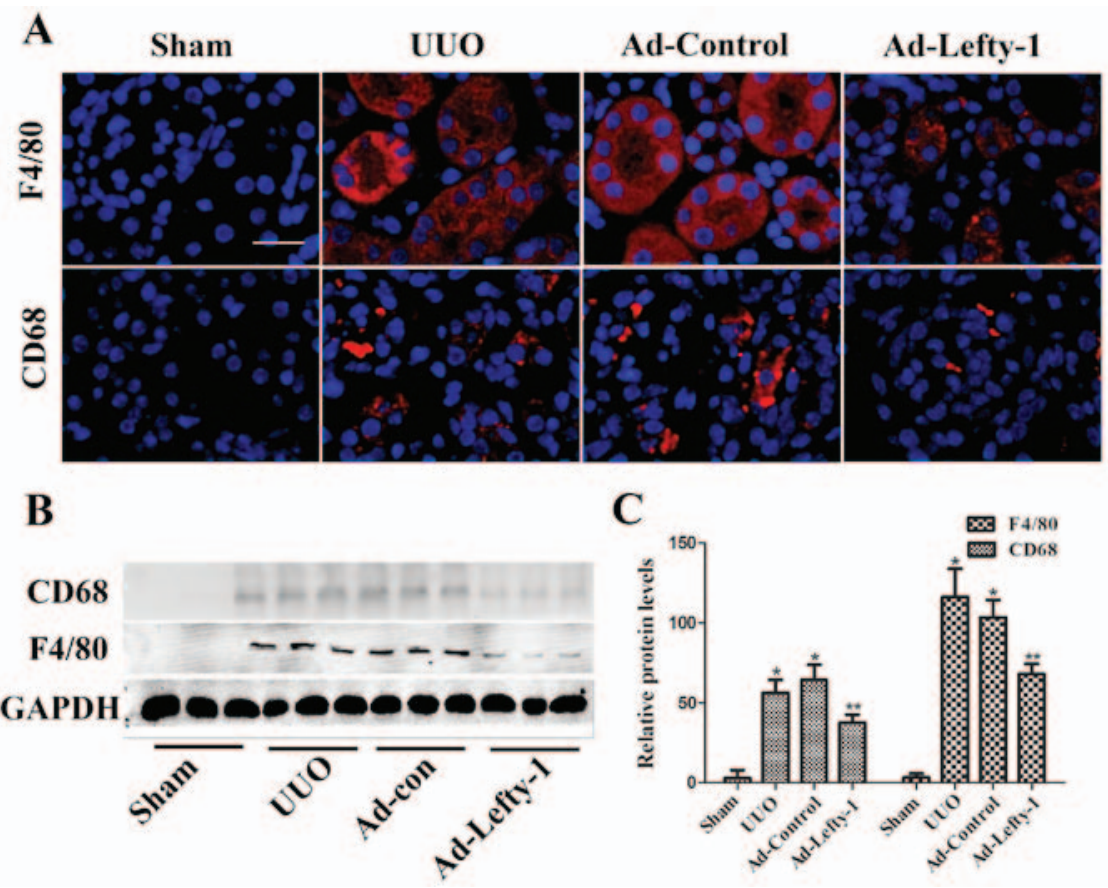

Figure 3. Immunofluorescence analysis of the effects of Lefty-1 on UUO-treated macrophage infiltration. (A) Comparative localization of CD68 and F4/80 (red). The macrophage markers CD68 and F4/80 were lowly expressed in kidney sections from mice treated with Ad-Lefty-1. Magnification, x200; scale bar, $20 \mu \mathrm{m}$ (B) Western blot analysis of the macrophage markers CD68 and F4/80. (C) Semi-quantitative analysis of western blotting. $\mathrm{n}=5{ }^{*} \mathrm{P}<0.001$ vs. the sham group; ${ }^{* *} \mathrm{P}<0.05$ vs. the UUO or UUO + Ad-control-treated groups. Ad, adenovirus; CD68, cluster of differentiation 68 ; Lefty-1, left-right determination factor 1; UUO, unilateral ureteral obstruction.

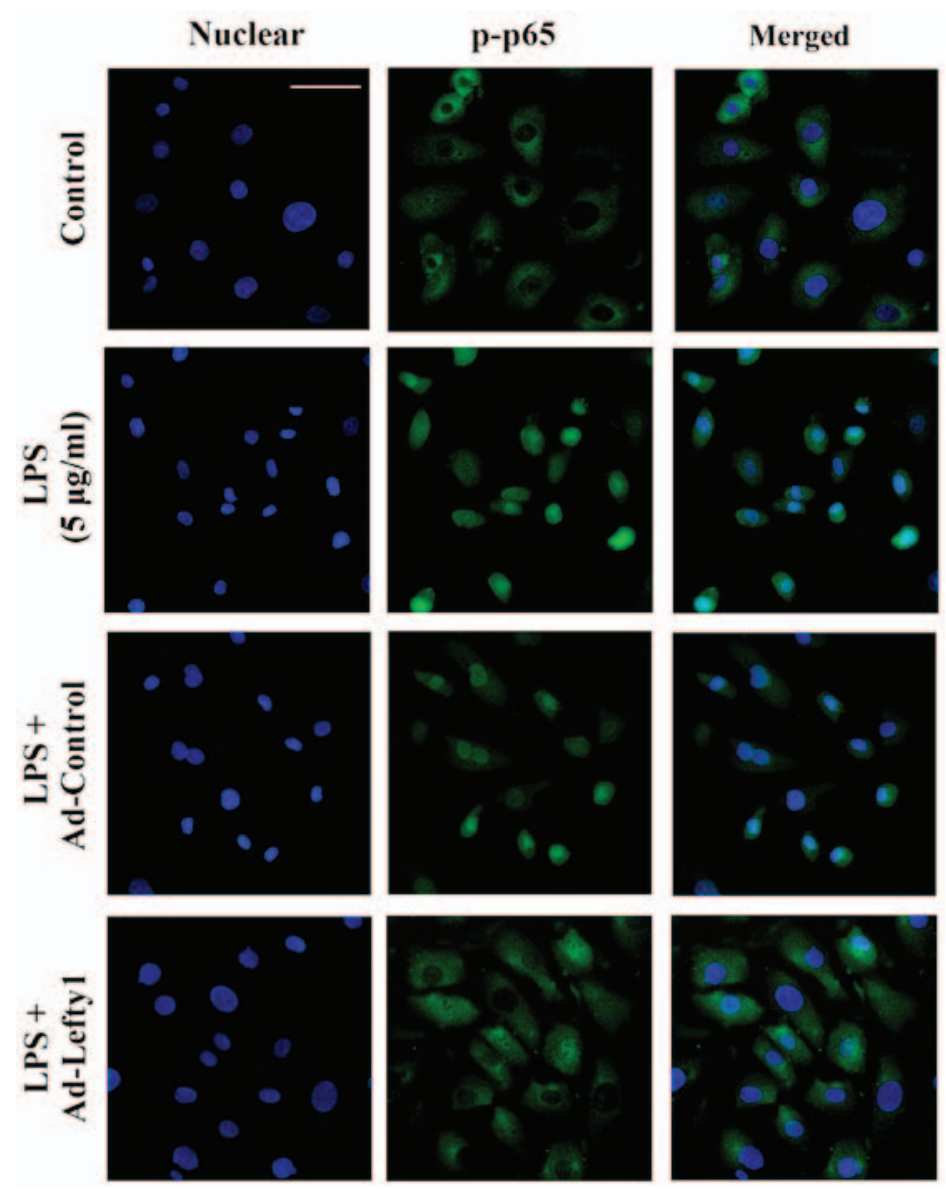

Figure 4. Effects of Lefty-1 on LPS ( $5 \mu \mathrm{g} / \mathrm{ml})$-induced NF- $\mathrm{BB}-\mathrm{p}-\mathrm{p} 65$ nuclear translocation in NRK-52E cells, as determined by immunofluorescence. Nuclei were stained with DAPI (blue) and NF-kB-p-p65 was stained green. Immunofluorescent images were captured under an Olympus BX51 fluorescence upright microscope (magnification, $\mathrm{x} 400$; scale bar, $40 \mu \mathrm{m}$.). Lefty-1 suppressed LPS-induced nuclear translocation of NF-кB. Representative images of three independent experiments

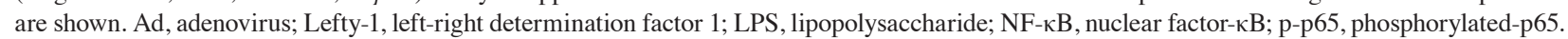



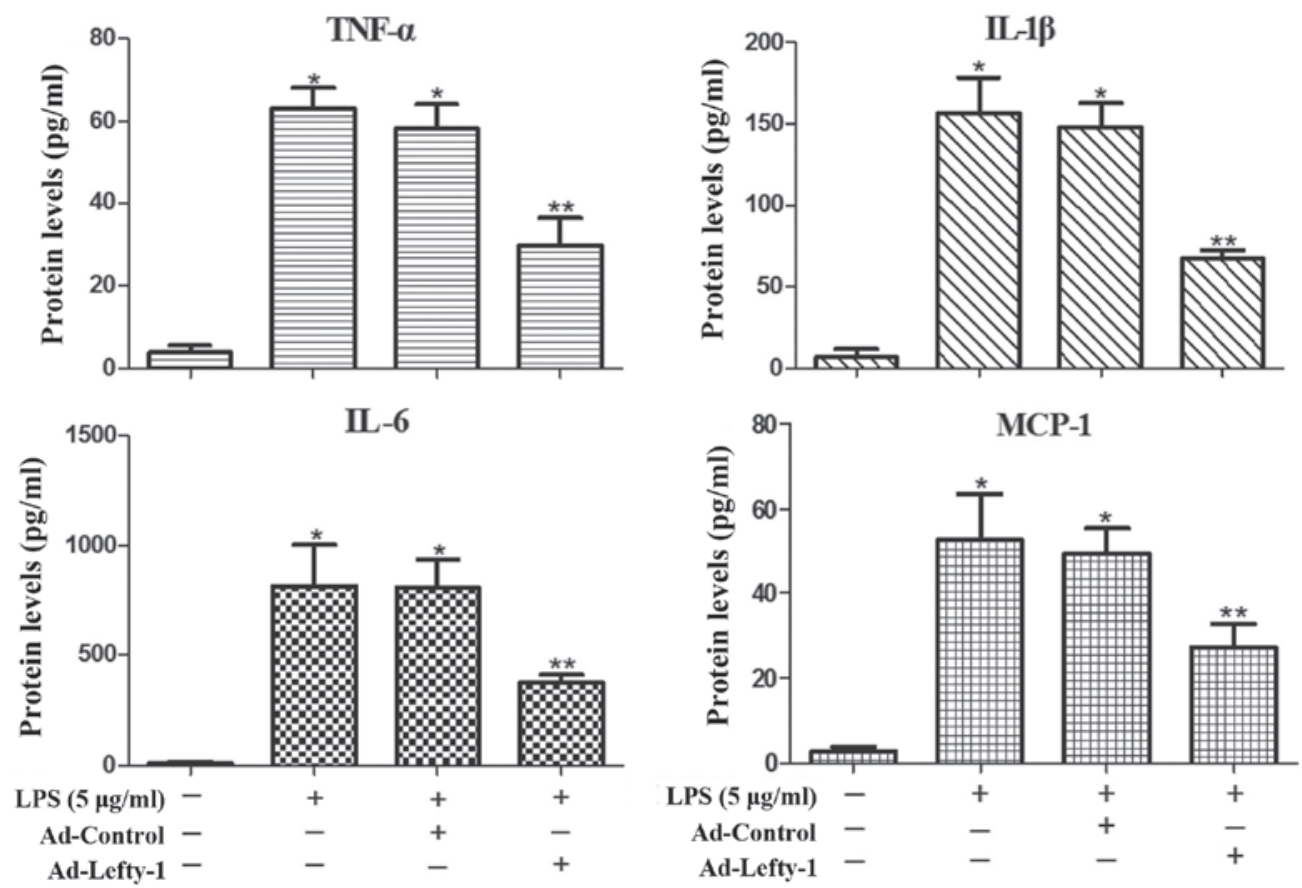

Figure 5. Anti-inflammatory effects of Lefty-1 on the LPS $(5 \mu \mathrm{g} / \mathrm{ml})$-induced expression of inflammatory proteins in NRK-52E cells. ELISA analyses indicated that the expression levels of IL-1 $\beta$, IL-6, TNF- $\alpha$ and MCP-1 were inhibited by Lefty-1 overexpression. Data are presented as the means \pm standard deviation of at least three independent experiments. $\mathrm{n}=5$. ${ }^{*} \mathrm{P}<0.001$ vs. the control group; ${ }^{* *} \mathrm{P}<0.05$ vs. the LPS $(5 \mu \mathrm{g} / \mathrm{ml})$ or LPS + Ad-control-treated groups. Ad, adenovirus; IL, interleukin; Lefty-1, left-right determination factor 1; LPS, lipopolysaccharide; MCP-1, monocyte chemotactic protein-1; TNF- $\alpha$, tumor necrosis factor- $\alpha$.

inhibited by Ad-Lefty-1, but not by Ad-control. The expression levels of fibrotic markers exhibited similar trends in NRK-52E cells; LPS-induced alterations were significantly inhibited by Ad-Lefty-1, but not by Ad-control (Fig. 6B and C).

Lefty-1 overexpression regulates $N F-\kappa B$ signaling pathways. Numerous reports have suggested that NF- $\kappa B$ signaling pathways are important for the regulation of macrophage infiltration and inflammatory cytokine expression (22). Therefore, the present study examined whether Lefty-1 may suppress $\mathrm{NF}-\mathrm{kB}$ pathways in vitro and in vivo. The results indicated that NF- $\kappa B-p-p 65$ protein expression was significantly inhibited by Ad-Lefty-1, whereas NF- $\mathrm{kB}-\mathrm{p} 65$ protein was not altered. In addition, IкB- $\alpha$ expression and its phosphorylation were detected. The expression levels of $\mathrm{p}$-IкB- $\alpha$ were increased in the LPS-stimulated group and were decreased in the Ad-Lefty- 1 group, whereas I $\mathrm{K} \mathrm{B}-\alpha$ protein expression was not altered. In addition, LPS-induced downregulation of Smad7 expression was reversed following Ad-Lefty-1 administration (Fig. 7A and B). Furthermore, NF-кB-p65 and Smad7 mRNA expression levels were examined in UUO mice with or without Ad-Lefty-1 treatment (Fig. 7C and D). The expression levels of NF-кB-p65 were not significantly altered in these groups. However, Smad7 expression levels were significantly downregulated in the UUO group and were significantly upregulated in the Ad-Lefty-1 group. These findings suggested that administering Ad-Lefty-1 could reverse UUO-induced downregulation of Smad7, which was similar to the previous observations in vitro. These data suggested that Lefty-1 may modulate the inflammatory response, probably via the Smad7-regulated NF- $\mathrm{BB}$ signaling pathway. Smad7-mediated inhibition of NF- $\kappa \mathrm{B}$ activation via I $\kappa \mathrm{B}-\alpha$ induction may be considered the central mechanism by which Lefty-1 prevents renal inflammation.

\section{Discussion}

The pathological process of inflammation, which is associated with acute and chronic renal injury, has an important role in structural and functional damage in various types of renal disease. Various inflammatory processes induce renal fibrotic damage, crescent formation and mesangial cell apoptosis. Renal tubulointerstitial inflammation culminates in fibrosis, which contributes to progressive renal disease. Emerging evidence has indicated that renal tubulointerstitial inflammation is closely associated with renal fibrosis. Therefore, inflammatory processes are considered to be involved in the pathogenesis of numerous renal diseases, including CKD and end-stage renal disease (23-25). These findings indicated that early renal inflammatory intervention is important. The pathogenesis of inflammation has been detected in numerous types of renal disease and has become a common target for novel drug development.

The present study provided credible evidence to suggest the importance of Lefty- 1 as a mediator of renal inflammation and fibrosis in vitro and in vivo. Based on the results of the present study, Lefty-1 may effectively inhibit expression of the NF- $\kappa B$ signaling pathway, interfere with IкB- $\alpha$ hydrolysis and nuclear translocation of the NF- $\kappa B-p-p 65$ protein, and serve an anti-inflammatory role. Furthermore, Lefty-1 was able to recover Smad7 expression, an important inhibitory Smad protein. A previous study reported that Smad7 can regulate numerous signal transduction pathways associated with inflammation (26). In addition, Lefty-1 is 
A

.
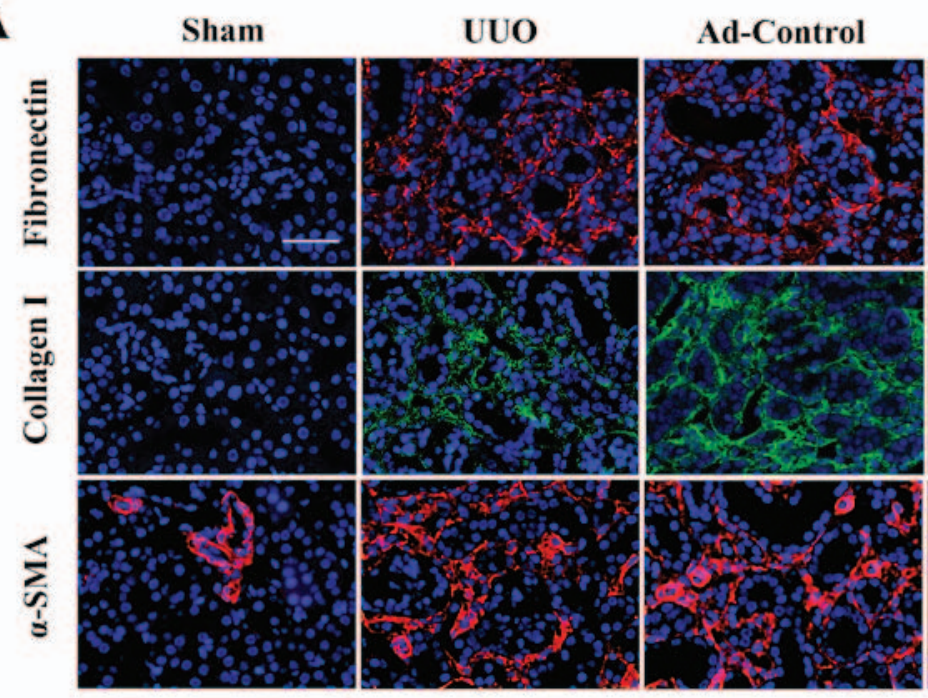

B

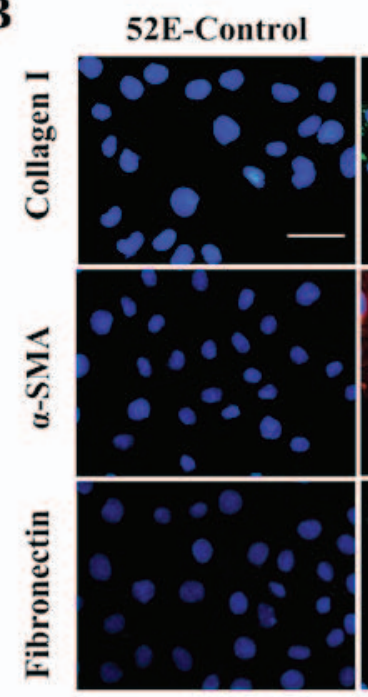

$\operatorname{LPS}(5 \mu \mathrm{g} / \mathrm{ml})$

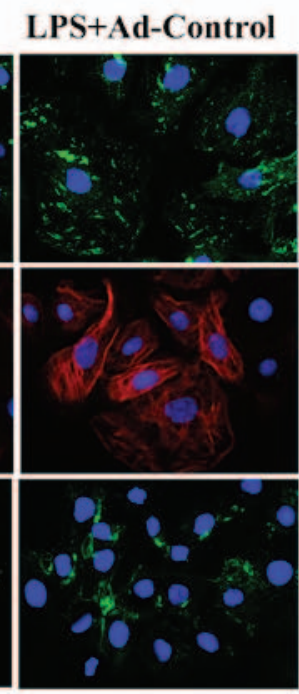

LPS+Ad-Lefty-1

C
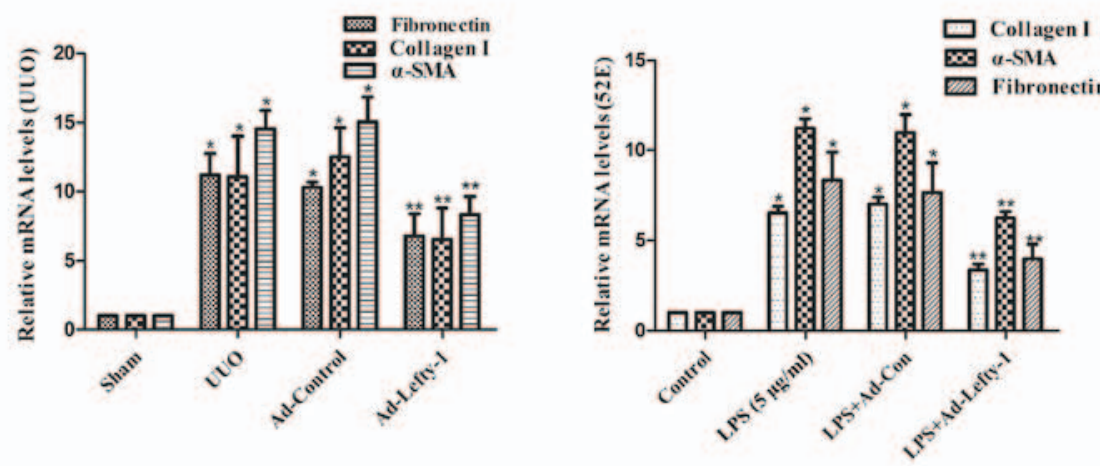

Figure 6. Immunofluorescence staining of fibronectin, collagen and $\alpha$-SMA in kidney tissues and NRK-52E cells. (A and B) Compared with in the UUO mice and LPS-treated NRK-52E cells, the expression levels of fibronectin, collagen I and $\alpha$-SMA were decreased in Ad-Lefty-1-infected groups. Ad-control had no significant effects. Magnification: (A) x200, scale bar, $20 \mu \mathrm{m}$; (B) x400, scale bar, $40 \mu \mathrm{m}$. (C) Reverse transcription-quantitative polymerase chain reaction analyses. $\mathrm{n}=5,{ }^{*} \mathrm{P}<0.001$ vs. the sham or control groups; ${ }^{* *} \mathrm{P}<0.05$ vs. the UUO, LPS $(5 \mu \mathrm{g} / \mathrm{ml})$, UUO + Ad-control or LPS + Ad-control-treated groups. $\alpha$-SMA, $\alpha$-smooth muscle actin; Ad, adenovirus; Lefty-1, left-right determination factor 1; LPS, lipopolysaccharide; UUO, unilateral ureteral obstruction.

an important regulator of TGF- $\beta$ signaling, which possesses various biological properties that are involved in mediating stem cell differentiation and embryonic development $(27,28)$. Based on these findings, the present study investigated the role of Lefty-1 in UUO- and LPS-induced renal expression of IL-1 $\beta$, IL-6, TNF- $\alpha$ and MCP-1 using in vivo and in vitro models, respectively. The present results demonstrated that Lefty-1 significantly inhibited proinflammatory cytokine and chemokine expression, and macrophage infiltration, in vivo and in vitro. Furthermore, protective effects of Lefty-1 were observed against renal inflammation, which may be due to the suppression of $\mathrm{NF}-\kappa \mathrm{B}$ signaling activation, which may be 


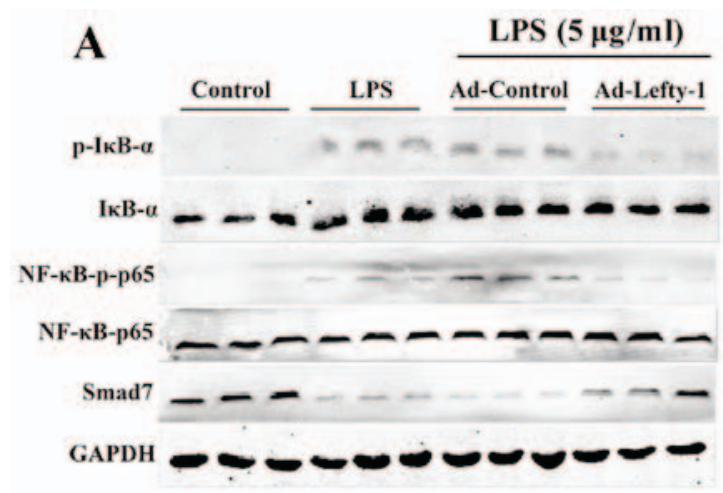

B

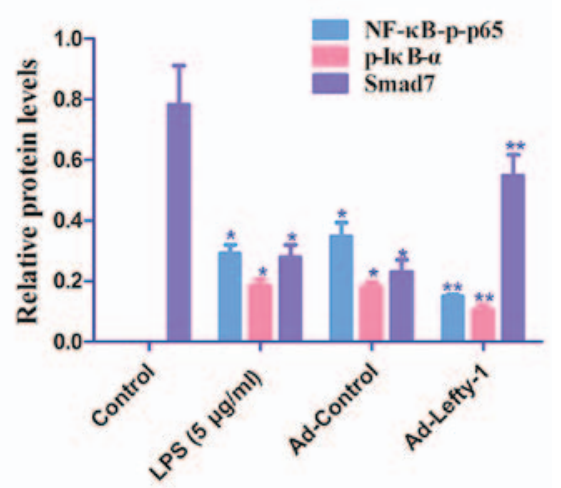

C

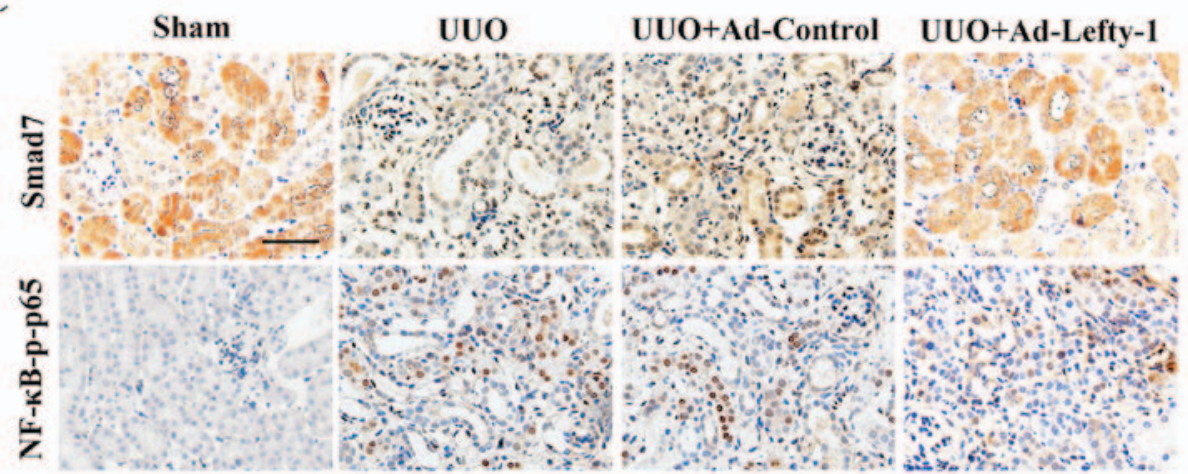

D
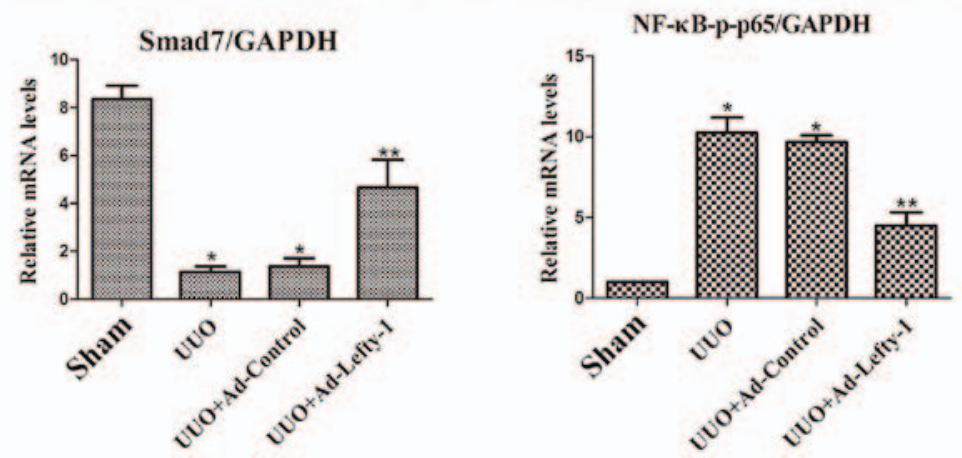

Figure 7. Overexpression of Lefty-1 modulates NF- $\kappa \mathrm{B} / \mathrm{Smad} 7$ signaling in renal tubulointerstitial inflammation. (A) Western blot analysis was conducted

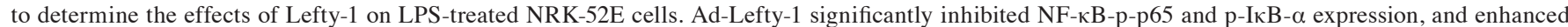
Smad7 expression. (B) Semi-quantitative analysis of western blotting. (C) Histological examination validated the in vitro results. Magnification, x200; scale bar, $20 \mu \mathrm{m}$ (D) Reverse transcription-quantitative polymerase chain reaction for NF- $\mathrm{kB}-\mathrm{p} 65$ and Smad7 expression. $\mathrm{n}=6$, ${ }^{\text {"P }} \mathrm{P}<0.001 \mathrm{vs}$. the sham or control groups; ${ }^{* *} \mathrm{P}<0.05$ vs. the UUO, LPS $(5 \mu \mathrm{g} / \mathrm{ml})$, UUO + Ad-control or LPS + Ad-control-treated groups. Ad, adenovirus; IкB- $\alpha, \mathrm{NF}-\kappa \mathrm{B}$ inhibitor- $\alpha$; Lefty-1, left-right determination factor 1; LPS, lipopolysaccharide; NF-кB, nuclear factor-kB; p-, phosphorylated; UUO, unilateral ureteral obstruction.

mediated by Smad7. These findings were consistent with the previous findings that Lefty is a novel tumor suppressor with anti-inflammatory potential (29).

The inflammatory process in the kidney is complex, and is closely associated with numerous types of cell signaling pathways and cytokines, which involve various cells, cytokines/chemokines, adhesion molecules and growth factors (30). Previous studies have focused on TGF- $\beta$ and epithelial or endothelial cells for mesenchymal transition in myofibroblast transformation, which leads to fibrosis (3). Inflammation is involved in the multi-stage process of fibrosis and is closely associated with scarring, where persistent and excessive tissue repair results in the replacement of normal parenchymal cells with fibrous tissue $(31,32)$. However, the exact mechanism underlying how renal tubulointerstitial inflammation leads to fibrosis has yet to be elucidated. Furthermore, current treatment of renal inflammatory diseases focuses on reducing inflammatory cytokines, and the use of nonspecific immunosuppressants, anticoagulants and anti-platelet drugs; however, such treatment is less effective (33). Enhancement of renal interstitial inflammation appears to be the main factor for renal fibrosis, particularly in obstructive nephropathy. Therefore, a better understanding of the renal interstitial inflammation-associated mechanism may promote the development of early treatment strategies for renal interstitial inflammation, and even for renal fibrosis and its associated ailments. Among all normal renal cells, renal tubular epithelial cells have an important role in renal inflammation $(34,35)$. Impaired renal tubular epithelial cells, which are able to secrete proinflammatory cytokines and a series of profibrotic factors, induce interstitial inflammation 
and vascular contraction that aggravates renal ischemia. This phenomenon leads to the apoptosis of renal tubular epithelial cells, renal tubular atrophy and renal interstitial fibrosis.

Activated NF- $\kappa \mathrm{B}$ signaling is the main signaling mechanism that activates and promotes macrophage infiltration and interstitial inflammation. Previous studies have reported that UUO- or LPS-mediated renal interstitial inflammation is associated with various intracellular signaling pathways, including $\mathrm{NF}-\kappa \mathrm{B}$, mitogen-activated protein kinase and other cascades (36-38). Therefore, $\mathrm{NF}-\kappa \mathrm{B}$ signaling is considered important for renal interstitial inflammation, as numerous molecules, including IL-1 $\beta$, IL- 6 , TNF- $\alpha$ and MCP-1, are involved in the early stage of the immune response, and each stage of inflammation is affected by $N F-\kappa B$ regulation. In quiescent cells, $\mathrm{NF}-\kappa \mathrm{B}$ and $\mathrm{I} \kappa \mathrm{B}$ form a complex, which is inactive in the cytoplasm. When the cells are stimulated by extracellular signals, I $\mathrm{B}$ kinase activation leads to I $\kappa \mathrm{B}$ phosphorylation, and $\mathrm{NF}-\kappa \mathrm{B}$ nuclear localization sites are exposed. The rapid translocation of dissociated NF- $\kappa \mathrm{B}$ to the nucleus, in combination with the specific $\kappa \mathrm{B}$ sequence, induces gene transcription. Therefore, $\mathrm{NF}-\kappa \mathrm{B}$-targeted therapeutic strategies may be effective in the treatment of renal inflammatory diseases; numerous anti-inflammatory agents achieve therapeutic effects by suppressing $\mathrm{NF}-\kappa \mathrm{B}$ signaling $(39,40)$. Smad7 is an inhibitory Smad that suppresses NF- $\kappa$ B-driven inflammatory responses in renal inflammation and fibrosis, and has garnered attention in recent years. Smad7 overexpression can induce I $\kappa \mathrm{B}-\alpha$, thereby inhibiting $\mathrm{NF}-\kappa \mathrm{B}$-induced renal inflammation. Therefore, Smad7 may have a potential therapeutic role in renal interstitial inflammation (41-43). In agreement with these observations, the present results indicated that the anti-inflammatory effects of Lefty-1 were partially involved with inhibition of $\mathrm{NF}-\kappa \mathrm{B}$ activation, by blocking nuclear translocation of the $\mathrm{NF}-\kappa \mathrm{B} / \mathrm{p} 65$ protein and $\mathrm{I} \kappa \mathrm{B}-\alpha$ degradation. In addition, Lefty-1 was able to recover Smad7 levels by inhibiting $N F-\kappa B$ activation. It is well accepted that TGF- $\beta$ may induce inhibition of $\mathrm{NF}-\kappa \mathrm{B}-$ mediated renal inflammation via induction of Smad7-dependent I $\mathrm{B}-\alpha$ expression (44). Notably, Smad7 expression is reduced in diseased kidneys, which causes an imbalance within the TGF- $\beta /$ Smads and $\mathrm{NF}-\kappa \mathrm{B}$ signaling pathways, resulting in the development of renal inflammation and fibrosis. A previous study, and the present study, indicated that Lefty-1 is a crucial mediator of the NF- $\kappa \mathrm{B}$ and TGF- $\beta /$ Smads pathways; these results revealed the numerous regulatory and balancing functions of Lefty-1 (45).

In conclusion, the association between renal interstitial inflammation and fibrosis is complex and significant in CKD pathogenesis. In particular, inflammation is often the initiating factor of fibrosis. Therefore, early intervention and control of renal interstitial inflammation are crucial in the treatment of renal fibrosis and CKD. The present findings provided clear evidence to suggest that Lefty-1 attenuated renal fibrosis by inhibiting renal interstitial inflammation. Further research revealed that Lefty-1 effectively inhibited NF- $\kappa$ B-p65 nuclear translocation, I $\mathrm{KB}-\alpha$ degradation and $\mathrm{Smad} 7$ degradation at the early stage of renal interstitial inflammation. These findings provide a novel theoretical basis for further development and utilization of Lefty-1 in the treatment of renal interstitial inflammation.

\section{References}

1. Ozaki E, Campbell M and Doyle SL: Targeting the NLRP3 inflammasome in chronic inflammatory diseases: Current perspectives. J Inflamm Res 8: 15-27, 2015.

2. Chen J, Zhao Y and Liu Y: The role of nucleotides and purinergic signaling in apoptotic cell clearance - implications for chronic inflammatory diseases. Front Immunol 5: 656, 2014.

3. Liu Y: Cellular and molecular mechanisms of renal fibrosis. Nat Rev Nephrol 7: 684-696, 2011.

4. Meng XM, Nikolic-Paterson DJ and Lan HY: Inflammatory processes in renal fibrosis. Nat Rev Nephrol 10: 493-503, 2014.

5. Lee SB and Kalluri R: Mechanistic connection between inflammation and fibrosis. Kidney Int Suppl 78: S22-S26, 2010.

6. Rodríguez-Iturbe B and García García G: The role of tubulointerstitial inflammation in the progression of chronic renal failure. Nephron Clin Pract 116: c81-c88, 2010.

7. Mayeux PR: Pathobiology of lipopolysaccharide. J Toxicol Environ Health 51: 415-435, 1997.

8. Bosshart $\mathrm{H}$ and Heinzelmann M: Targeting bacterial endotoxin: Two sides of a coin. Ann N Y Acad Sci 1096: 1-17, 2007.

9. Abdel-Bakky MS, Hammad MA, Walker LA and Ashfaq MK: Silencing of tissue factor by antisense deoxyoligonucleotide prevents monocrotaline/LPS renal injury in mice. Arch Toxicol 85: 1245-1256, 2011.

10. Zhong F, Chen H, Jin Y, Guo S, Wang W and Chen N: Analysis of the gene expression profile of curcumin-treated kidney on endotoxin-induced renal inflammation. Inflammation 36: 80-93, 2013.

11. Zhang J, Zheng L, Yuan X, Liu C, Yuan Q, Xie F, Qiu S, Peng Z, Tang Y, Meng J, et al: Mefunidone ameliorates renal inflammation and tubulointerstitial fibrosis via suppression of IKK $\beta$ phosphorylation. Int J Biochem Cell Biol 80: 109-118, 2016.

12. Zhou X, Sun X, Gong X, Yang Y, Chen C, Shan G and Yao Q: Astragaloside IV from Astragalus membranaceus ameliorates renal interstitial fibrosis by inhibiting inflammation via TLR4/NF-кB in vivo and in vitro. Int Immunopharmacol 42: 18-24, 2017.

13. Tabibzadeh S and Hemmati-Brivanlou A: Lefty at the crossroads of 'stemness' and differentiative events. Stem Cells 24: 1998-2006, 2006.

14. Ulloa L and Tabibzadeh S: Lefty inhibits receptor-regulated Smad phosphorylation induced by the activated transforming growth factor-beta receptor. J Biol Chem 276: 21397-21404, 2001.

15. Li H, Li H, Bai L and Yu H: Lefty inhibits in vitro decidualization by regulating P57 and cyclin D1 expressions. Cell Biochem Funct 32: 657-664, 2014.

16. Cavallari C, Fonsato V, Herrera MB, Bruno S, Tetta C and Camussi G: Role of Lefty in the anti tumor activity of human adult liver stem cells. Oncogene 32: 819-826, 2013.

17. Tang M, Naidu D, Hearing P, Handwerger S and Tabibzadeh S: LEFTY, a member of the transforming growth factor-beta superfamily, inhibits uterine stromal cell differentiation: A novel autocrine role. Endocrinology 151: 1320-1330, 2010.

18. Xu C, Xu M, Wang W and Zhang J: Leftyl alleviates renal tubulointerstitial injury in mice with unilateral ureteral obstruction. Mol Med Rep 13: 901-908, 2016.

19. Ghayur A, Liu L, Kolb M, Chawla A, Lambe S, Kapoor A and Margetts PJ: Adenovirus-mediated gene transfer of TGF- $\beta 1$ to the renal glomeruli leads to proteinuria. Am J Pathol 180: 940-951, 2012.

20. Georgi MK, Vigilance J, Dewar AM and Frame MD: Terminal arteriolar network structure/function and plasma cytokine levels in $\mathrm{db} / \mathrm{db}$ and ob/ob mouse skeletal muscle. Microcirculation 18: 238-251, 2011.

21. Livak KJ and Schmittgen TD: Analysis of relative gene expression data using real-time quantitative PCR and the 2(-Delta Delta C(T)) Method. Methods 25: 402-408, 2001.

22. Liu W, Zhu $H$ and Fang H: Propofol potentiates sevoflurane-induced inhibition of nuclear factor- $\kappa \mathrm{B}$-mediated inflammatory responses and regulation of mitogen-activated protein kinases pathways via Toll-like receptor 4 signaling in lipopolysaccharide-induced acute lung injury in mice. Am J Med Sci 354, 493-505, 2017.

23. Anders HJ and Ryu M: Renal microenvironments and macrophage phenotypes determine progression or resolution of renal inflammation and fibrosis. Kidney Int 80: 915-925, 2011.

24. Lan HY: Diverse roles of TGF- $\beta /$ Smads in renal fibrosis and inflammation. Int J Biol Sci 7: 1056-1067, 2011

25. Brown NJ: Contribution of aldosterone to cardiovascular and renal inflammation and fibrosis. Nat Rev Nephrol 9: 459-469, 2013. 
26. Zhu L, Chen S and Chen Y: Unraveling the biological functions of Smad7 with mouse models. Cell Biosci 1: 44, 2011.

27. Rosa A, Papaioannou MD, Krzyspiak JE and Brivanlou AH: miR-373 is regulated by TGF $\beta$ signaling and promotes mesendoderm differentiation in human Embryonic Stem Cells. Dev Biol 391: 81-88, 2014.

28. Hu H, Deng F, Liu Y, Chen M, Zhang X, Sun X, Dong Z, Liu X and Ge J: Characterization and retinal neuron differentiation of WERI-Rb1 cancer stem cells. Mol Vis 18: 2388-2397, 2012.

29. Miyata N, Azuma T, Hozawa S, Higuchi H, Yokoyama A, Kabashima A, Igarashi T, Saeki K and Hibi T: Transforming growth factor $\beta$ and Ras/MEK/ERK signaling regulate the expression level of a novel tumor suppressor Lefty. Pancreas 41: 745-752, 2012.

30. Manresa MC, Godson C and Taylor CT: Hypoxia-sensitive pathways in inflammation-driven fibrosis. Am J Physiol Regul Integr Comp Physiol 307: R1369-R1380, 2014.

31. Torres IB, Moreso F, Sarró E, Meseguer A and Serón D: The Interplay between inflammation and fibrosis in kidney transplantation. BioMed Res Int 2014: 750602, 2014.

32. Manucha W and Vallés PG: Apoptosis modulated by oxidative stress and inflammation during obstructive nephropathy. Inflamm Allergy Drug Targets 11: 303-312, 2012.

33. Declèves AE and Sharma K: Novel targets of antifibrotic and anti-inflammatory treatment in CKD. Nat Rev Nephrol 10: 257-267, 2014

34. Bolisetty S, Zarjou A, Hull TD, Traylor AM, Perianayagam A, Joseph R, Kamal AI, Arosio P, Soares MP, Jeney V, et al: Macrophage and epithelial cell $\mathrm{H}$-ferritin expression regulates renal inflammation. Kidney Int 88: 95-108, 2015.

35. Oh SW, Lee YM, Kim S, Chin HJ, Chae DW and Na KY: Cobalt chloride attenuates oxidative stress and inflammation through $\mathrm{NF}-\kappa \mathrm{B}$ inhibition in human renal proximal tubular epithelial cells. J Korean Med Sci 29 (Suppl 2): S139-S145, 2014.

36. Zhong F, Chen H, Han L, Jin Y and Wang W: Curcumin attenuates lipopolysaccharide-induced renal inflammation. Biol Pharm Bull 34: 226-232, 2011.

37. Hu F, Liang W, Ren Z, Wang G and Ding G: Surfactant protein D inhibits lipopolysaccharide-induced monocyte chemoattractant protein-1 expression in human renal tubular epithelial cells: Implication for tubulointerstitial fibrosis. Clin Exp Immunol 167: $514-522,2012$.
38. Choi YH, Kim GY and Lee HH: Anti-inflammatory effects of cordycepin in lipopolysaccharide-stimulated RAW 264.7 macrophages through Toll-like receptor 4-mediated suppression of mitogen-activated protein kinases and $N F-\kappa B$ signaling pathways. Drug Des Devel Ther 8: 1941-1953, 2014.

39. Oh YC, Jeong YH, Ha JH, Cho WK and Ma JY: Oryeongsan inhibits LPS-induced production of inflammatory mediators via blockade of the NF-kappaB, MAPK pathways and leads to HO-1 induction in macrophage cells. BMC Complement Altern Med 14: 242, 2014.

40. Suh SH, Lee KE, Kim IJ, Kim O, Kim CS, Choi JS, Choi HI, Bae EH, Ma SK, Lee JU, et al: Alpha-lipoic acid attenuates lipopolysaccharide-induced kidney injury. Clin Exp Nephrol 19: 82-91, 2015

41. Yan X and Chen YG: Smad7: Not only a regulator, but also a cross-talk mediator of TGF- $\beta$ signalling. Biochem J 434: 1-10, 2011.

42. Meng XM, Huang XR, Xiao J, Chung AC, Qin W, Chen HY and Lan HY: Disruption of Smad4 impairs TGF- $\beta / \mathrm{Smad} 3$ and Smad7 transcriptional regulation during renal inflammation and fibrosis in vivo and in vitro. Kidney Int 81: 266-279, 2012.

43. Liu GX, Li YQ, Huang XR, Wei L, Chen HY, Shi YJ, Heuchel RL and Lan HY: Disruption of Smad7 promotes ANG II-mediated renal inflammation and fibrosis via Sp1-TGF- $\beta / \mathrm{Smad} 3-\mathrm{NF}$. кB-dependent mechanisms in mice. PLoS One 8: e53573, 2013.

44. Ng YY, Hou CC, Wang W, Huang XR and Lan HY: Blockade of NFkappaB activation and renal inflammation by ultrasound-mediated gene transfer of Smad7 in rat remnant kidney. Kidney Int Suppl 67: S83-S91, 2005.

45. Zhang L, Zhang J, Xu C, Zhou X, Wang W, Zheng R, Hu W and Wu P: Lefty-1 alleviates TGF- $\beta 1$-induced fibroblast-myofibroblast transdifferentiation in NRK-49F cells. Drug Des Devel Ther 9: 4669-4678, 2015.

This work is licensed under a Creative Commons Attribution-NonCommercial-NoDerivatives 4.0 International (CC BY-NC-ND 4.0) License. 